\title{
Systems of China Meteorological Disaster Emergency Response*
}

\author{
Chen Zhenghong \\ China Meteorological Administration Training Centre, Beijing, China \\ Email: chenzhengh@cma.gov.cn
}

Received November $8^{\text {th }}$, 2012; revised January $2^{\text {nd }}$, 2013; accepted January $15^{\text {th }}$, 2013

\begin{abstract}
Copyright (c) 2013 Chen Zhenghong. This is an open access article distributed under the Creative Commons Attribution License, which permits unrestricted use, distribution, and reproduction in any medium, provided the original work is properly cited.
\end{abstract}

\begin{abstract}
China Meteorological Administration (CMA) and the local Meteorological Bureaus, have set up Emergency Management Office and associated organizations for weather emergency in the Chinese inland. A suite of relatively comprehensive system for meteorological disasters and some emergency response programs have also been implemented by CMA. To illustrate how the mechanism operates, this paper presents two cases with one involving the Olympics weather emergency services in August 2008 and the other the low-temperature and snow disaster emergency response in Southern China in early 2008. I conclude that weather emergency management in China should follow the scientific emergency management principle, as well as the prevention-oriented and emergency rescue-combined principle.
\end{abstract}

Keywords: Meteorological Disasters; Meteorological Emergency Response; Emergency Response Principle

\section{Introduction}

\section{General Descriptions on Metrological Disasters in China}

China is one of countries in the world with serious natural meteorological disasters including typhoon, torrential rain, drought, high temperature and heat wave, sand storm, thunder and so on. In recent years, the global climate continues to warm, resulting in frequent occurrences of a large variety of extreme weather events. Each year the direct economical loss resulting from meteorological disasters is approximately 22.8 billion USD according to the statistics in 1990-2006, which on the average accounts for $1 \%$ - 3\% of GDP. Chinese meteorological disasters have significantly increased and resulted in many adverse impacts on society (Figure 1). That puts forward new and higher requirements on Chinese weather emergency work.

\section{Emergency Management Agencies of CMA}

Emergency management is a very important task and function of Chinese government. It has especially been so since SARS in 2003. Emergency management agencies of CMA are a part of the whole emergency management system set up in accordance with national requirements (Information Office of the Chinese State Council, 2009). In 2005, CMA established the Emergency Management Office. The Bureau of Meteorology of every province, autonomous region, and municipality in the Chinese mainland followed by setting up corresponding emergency management offices. And over 300 local meteorological bureaus and even county-level meteorological bureaus also established all kinds of offices and units in support to emergency meteorological response.

\footnotetext{
*Short paper.
}

CMA has also paid attention to emergency management mechanisms and standard processes. The function of CMA Emergency Management Office initiates and coordinates meteorological emergency issues including disaster monitoring, forecasting, warning, and assessment. The office is also in charge of investigating meteorological disasters, collecting relevant information, and doing statistical analysis. The provincial and local meteorological bureaus emergency offices do the same work in their areas.

\section{Meteorological Emergency Response Systems in CMA}

Laws and institutions are the key factors for disaster mitigation. The Meteorological Law of People's Republic of China was promulgated on 1 January 2000 as the basic law for Chinese Meteorological Emergency Response Systems. And the Emer-

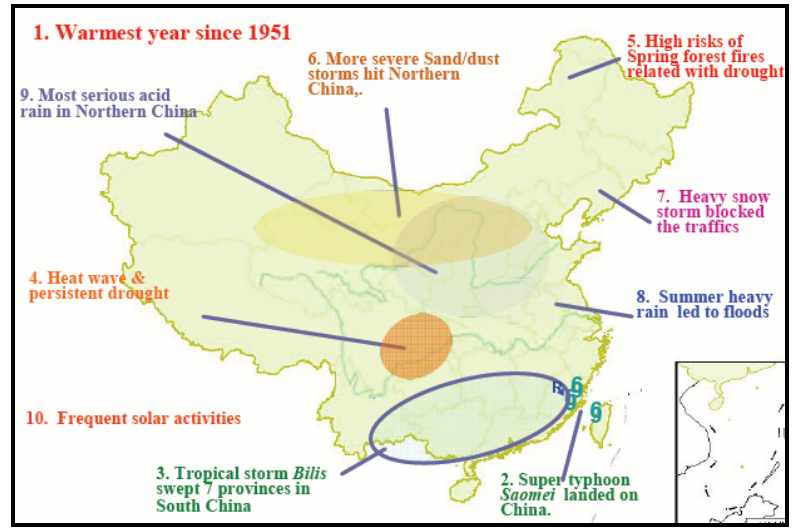

Figure 1.

China's mainly meteorological disasters (from Jiao, 2007). 
gency Response Law of the People's Republic of China came into effect on 1 November 2007. CMA has made and revised 16 regulations, 4 national standards and over 40 industrial standards on meteorological emergency activities and other legal documents according to the two key laws. Furthermore, the local legislators and governments have issued over 70 bylaws and regulations for meteorological disasters.

CMA makes it its top priority to develop meteorological emergency response and plans. Chinese government published National Overall Emergency Response Program for Emergent Public Events. CMA has also issued an Emergency Response Plan for Major Meteorological Disaster Early Warning and Measures on Issuing Emergent Meteorological Disaster Early Warning Signals and so on (Figure 2).

In addition, CMA organized and implemented lots of contingency measures and plans for meteorological disasters including Major Weather Disaster Warning Contingency Plan, Significant Meteorological Disaster Information Submitting Standard and Disposal Methods, Emergency Meteorological Support and Services for Public Incidents (Trial Implementation), Survey and Evaluation Rule of Collection on Meteorological Disasters, Metropolises Disaster Monitoring and Weather Forecasting Service Program, etc. Last but not least, CMA strengthened safely measure such as China Meteorological Administration Anti-terrorism and Plans for Handling Emergency Situations.

Chinese provincial and local meteorological administrations also have formulated emergent meteorological service measures and plans for emergent public events including nuclear substance dispersion, leakage of hazardous chemicals, geological disasters, and so on.

\section{Case Studies}

There are a lot of emergency cases concerning weather emergency response in China, such as emergency severs for typhoons, weather emergency response for Olympic torch ascent on Everest, etc. Here we only focus on two cases.

\section{Emergency Meteorological Service of 2008 Olympics}

Emergency Meteorological Service of 2008 Olympics refers to the prompt response to heavy rain, hail, high winds during the Olympic Games. For example, if hail, rain, and other emergency weather events happened during the opening and closing ceremonies, the CMA would use weather modification technology to alleviate the negative impact of those events on the ceremonies. To ensure a smooth process of the opening and closing ceremonies, CMA has established the Modification Weather Operations Program for 2008 Olympic Games.

Emergency Meteorological Service of 2008 Olympics also included emergency response actions for poisonous pollution (Wu et al., 2009). Therefore, China Meteorological Administration

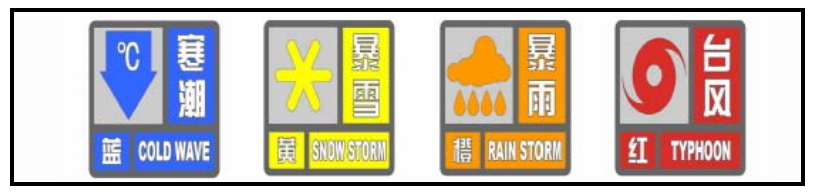

Figure 2.

Early WARNING SIGNALS of some meteorological disasters (from website of CMA: http://www.cma.gov.cn). developed Olympic Environment Conditions Emergency Response Plan and organized the environmental emergency response. This is a successful case of meteorological emergency response.

\section{China Southern Freezing Rain and Snow Disaster Response}

Freezing rain and snow in southern China was the most serious emergency after the event of "SARS" in China. In January 2008, persistent freezing rain and snow disaster has struck and severely affected most parts of southern China, including $\mathrm{Hu}-$ nan, Hubei, Guizhou, Guangxi, Jiangxi, Anhui, and some other provinces (Lin et al., 2009). At first, this was just a natural disaster in the context of global climate change. However, the heavy snow disrupted the normal operation of urban infrastructure, resulting in large-scale power outage in Guizhou, Hunan, Jiangxi, and other places. Especially, the transportation railway systems in Beijing-Guangzhou and Beijing-Zhuhai were blocked and shut down. A number of urban water supply pipelines were frost crack and communications were out of work.

On January 21, 2008, the Chinese State Council's Emergency Office issued emergency information in response to this snowstorm. However, various departments took different response measures in their sectors. At that time, it was important to implement integrated decision-making. The snow and ice led to wire disruption, which in turn led to lots of trains delay.

This disaster highlighted the vulnerability of the infrastructure in China South. A snow disaster led to north-south artery interruption and poor communication. Especially, the traffic information dissemination became fuzzy, which made the disaster worse under the traffic chaos. For example, the travelers who stood in temporary resettlement sites should have gotten more detailed information and quick guidelines, but many travelers had to go to the station for information about the latest situation due to a lack of broadcasting in the station square. Such operational malfunction in emergency response complicated the natural disaster, with a technological disaster, and enlarged the negative impact on social life.

However, many government branches in south China had no sense of crisis (Sun, 2009) because such cold weather events usually occur in north China. Therefore, these local governments seldom considered the impacts of strong snowstorm on local production and people's life. For instance, the majority of thermal power plants in China have just 10 to 12 days inventories as normal coal inventory, and 5 days as the warning line. In the United States, by contrast, coal power inventories can maintain at least 40 days, even surviving the general severe weather events. In this regard, China's disaster resilience is pretty fragile in comparison with those in foreign countries.

\section{Conclusion}

The legal construction of emergency meteorological disaster in Chinese mainland must consider the general principles of legal construction as well as the following several important principles.

Firstly, the meteorological emergency response and legal system construction must be based on scientific principles. We should take full advantage of meteorological science and technology. We should focus on disaster monitoring, and forecasting (Wang et al., 2007). 
Secondly, good preventive work can significantly reduce the losses resulted from sudden weather disasters. And it will be helpful in disaster mitigation, emergency response, and disaster reconstruction. The early-warning system should also be largely improved (Li et al., 2009).

Thirdly, meteorological emergency response plans can be controlled within 500 words or so, which should be easy for people to grasp the key rules and be familiar with the specific operations. Meteorological emergency response plans should define basic preparation specifications, including structural framework, reporting procedures, style formats, and relevant annexes. In addition, meteorological emergency response plans should include the knowledge of meteorological disaster prevention, which should go "into the enterprise, into the rural area, into school, and into the community".

\section{Acknowledgements}

This work has been supported by National Natural Science Foundation of China No. 41220001 (Z. H. Chen) and Urban Meteorological Research Foundation of Beijing No.
UMRF201203.

\section{REFERENCES}

Jiao, M. Y. (2007). National emergency management of meteorological disasters. Geneva: CMA Report (interior).

Lin, L. X. et al. (2009). Disaster and emergency response of the cryogenic freezing rain and snow weather in Guangdong in 2008. Meteorological Monthly, 35, 26-33.

Li, Y. et al. (2009). Emergency mobile automotive system in meteorology and its application in emergency meteorology service. Informatization Research, 35, 1-5.

Sun, B. (2009). Study on disaster emergency management system in city. Journal of Natural Disasters, 18, 39-44.

Wang, B. et al. (2007). The design based on the communications system of 3G network on the meteorological emergency commanding vehicle. Journal of Meteorological Research and Application, 28, 37-39.

Wu, Y. B., Liu, W. et al. (2009). The application of atmospheric diffusion model in the emergency meteorological service. Guangdong Meteorology, 31, 4-6. 